\title{
PRODUÇÃO E ANÁLISE ECONÔMICA DO MARACUJAZEIRO-AMARELO SỎB DIFERENTES DENSIDADES E DESBASTE DE PLANTAS ${ }^{1}$
}

\author{
Production and economical analysis of the yellow passion fruit plant under \\ different densities and pruning
}

\author{
Sebastião Elviro de Araújo Neto², Valter Carvalho de Andrade Júnior³, José Darlan Ramos', \\ José Carlos Moraes Rufini ${ }^{5}$, Vander Mendonça ${ }^{6}$
}

\begin{abstract}
RESUMO
Objetivou-se com este trabalho avaliar o efeito de diferentes densidades de plantio na produção e rentabilidade econômica do maracujazeiro-amarelo (Passiflora edulis Sims f. flavicarpa Degener). O experimento foi instalado e conduzido em pomar comercial da Fazenda Sant'Ana, município de São Tiago-MG, com plantio em outubro de 2001 e colheitas no primeiro semestre de 2002, 2003 e 2004. O delineamento experimental utilizado foi o de blocos casualizados com sete tratamentos e quatro repetições. Os tratamentos constituíram-se de diferentes densidades na linha de plantio: $\mathrm{T} 1=1,0 \mathrm{~m}$ (3.330 plantas $/ \mathrm{ha}), \mathrm{T} 2=2,0 \mathrm{~m}(1.660$ plantas $/ \mathrm{ha}), \mathrm{T} 3=3,0 \mathrm{~m}(1.110 \mathrm{plantas} / \mathrm{ha})$, $\mathrm{T} 4=4,0 \mathrm{~m}$ (830 plantas/ha), T5= 1,0 m (3.330/1.660 plantas/ha), T6=1,5 m (2.220/1.110 plantas/ha) e T7=2,0 m (1.660/830 plantas/ ha). Nos tratamentos T5, T6 e T7, foi feito desbaste de plantas alternadas logo após o término da colheita da primeira safra. A produtividade acumulada das três safras, revelou menor produtividade para o sistema menos adensado com 25,6 t/ha, não havendo diferença entre os demais tratamentos, com média de 27,96 t/ha. A máxima eficiência econômica foi alcançada na densidade de 1.110 plantas/ha, com receita líquida de $\mathrm{R} \$ 2.637,56 /$ ha, considerando o sistema de comercialização "Mista" (Industria/Mesa), com preço médio de $\mathrm{R} \$ 0,55 / \mathrm{kg}$, pois a comercialização exclusiva para a indústria ( $\mathrm{R} \$ 0,40 / \mathrm{kg}$ ) proporcionou um situação de resíduo.
\end{abstract}

Termos para indexação: Passiflora edulis f. flavicarpa produtividade, plantio.

\begin{abstract}
The objective of this research was to evaluate the effect of different planting densities on production and economical profitability of yellow passion fruit plant (Passiflora edulis Sims f. flavicarpa Degener). The experiment was installed and led in a commercial orchard in Sant'ana Farm, municipal district of São Tiago, Minas Gerais, Brazil, with planting in October of 2001 and harvest began in the first semester of 2002, 2003 and 2004. The experimental design was in of randomized blocks with seven treatments and four repetitions. The treatments were constituted of different planting densities: $\mathrm{T} 1=1.0 \mathrm{~m}(3,330 \mathrm{plants} / \mathrm{ha})$; T2 $=$ $2.0 \mathrm{~m}$ (1,660 plants/ha); T3 = $3.0 \mathrm{~m}(1,110$ plants/ha); T4 = $4.0 \mathrm{~m}(830$ plants $/ \mathrm{ha}) ; \mathrm{T} 5=1.0 \mathrm{~m}(3,330 / 1,660 \mathrm{plants} / \mathrm{ha}) \mathrm{T} 6=1.5 \mathrm{~m}$ $(2,220 / 1,110$ plants/ha) e T7 $=2.0 \mathrm{~m}(1,660 / 830$ plants/ha). The treatments T5, T6 and T7, were hewed alternately right after the first crop's harvest. The accumulated productivity of the three crops, revealed smaller productivity for the lowers density system $(3.0 \mathrm{x}$ $4.0 \mathrm{~m}$ ), with $25.6 \mathrm{t} / \mathrm{ha}$, and average of $27.96 \mathrm{t} / \mathrm{ha}$ for the other treatments. The maxim economical efficiency was reached in the density of 1,110 plants/ha, with liquid revenue of $\mathrm{R} \$ 2,637.56 / \mathrm{ha}$, considering a Mixed system of "commercialization" (elaborate/fresh fruit), with medium price of $\mathrm{R} \$ 0.55 / \mathrm{kg}$, due to the exclusive commercialization for it elaborates ( $\mathrm{R} \$ 0.40 / \mathrm{kg}$ ) it provided a situation of negative residue in all the treatments.
\end{abstract}

Index terms: Passiflora edulis f. flavicarpa, productivity, planting.

(Recebido para publicação em 4 de novembro de 2004 e aprovado em 18 de outubro de 2005)

\section{INTRODUÇÃO}

O maracujazeiro amarelo (Passiflora edulis Sims $\mathrm{f}$. flavicarpa Degener) é uma planta trepadeira, robusta, de rápido desenvolvimento, que pode alcançar até $10 \mathrm{~m}$ de comprimento (RUGGIERO et al., 1996). Tem crescimento contínuo durante a primavera e verão, com fluxos de vegetação seguidos por fluxos de produção, havendo competição entre o crescimento vegetativo e o reprodutivo (MENZEL et al., 1993). Estas características permitem a adoção de grandes espaçamentos entre as plantas. Motivo pelo qual em outrora se recomendavam espaçamentos de 2,5 a 4,0 m entre as linhas e de 4,0 a 6,0 m entre plantas na linha de plantio (GOMES, 1987; RAMOS, 1986). Mas, por ser uma cultura semiperene, com ciclos de dois a quatro anos, a decisão sobre qual seja o espaçamento por ocasião

${ }^{1}$ Trabalho extraído de parte da Tese de Doutorado apresentada à Universidade Federal de Lavras/UFLA pelo primeiro autor - bolsista da CAPES.

${ }^{2}$ D.Sc. Fitotecnia., Professor de Fruticultura do Departamento de Ciências Agrárias da Universidade Federal do Acre/UFAC - Rio Branco,Acre 69.915-900 - selviro@ufac.br

${ }^{3}$ Engenheiro Agrônomo, D.Sc. Fitotecnia, Professor da Universidade Federal dos Vales do Jequitinhonha e Mucuri/UFVJM - valter@fafed.br

${ }^{4}$ Engenheiro Agrônomo, D.Sc., Fitotecnia, Professor Fruticultura da Universidade Federal de Lavras/UFLA - darlan@ufla.br

${ }^{5}$ Engenheiro Agrônomo, D.Sc., Fitotecnia., Professsor da UNIVALE - Governador Valadares, MG - jcrufini@mgconecta.com.br

${ }^{6}$ Engenheiro Agrônomo, D.Sc., Fitotecnia, Professor da Universidade Estadual do Matogrosso do Sul - vanderm@uems.br 
do plantio repercutirá durante todo o ciclo do pomar.

A densidade de plantio em maracujazeiro interfere principalmente na produtividade (PACE \& ARAÚJO, 1981) e lucratividade (KITS et al., 1996), mas, não interfere na qualidade dos frutos (MANICA et al., 1989).

Análises econômicas comparando diferentes densidades de plantas tendem a converter as variações produtivas em unidades monetárias facilitando a decisão do produtor. Contudo, apesar das indicações de que plantios adensados são mais produtivos (LEDERMAN et al., 1986; PACE \& ARAÚJO, 1981), principalmente por antecipar a produção já na primeira safra, Kits et al. (1996) concluem que a produtividade da cultura não deve ser a única característica avaliada, pois o adensamento de plantio está diretamente relacionado com custo de produção, e dessa forma, a rentabilidade do pomar aumenta com o aumento da densidade de plantas até atingir um ponto máximo, e decai a partir desse ponto.

Torna-se evidente a dificuldade na decisão de se adotar um espaçamento que proporcione boa produtividade para o maracujazeiro, principalmente pela escassez de trabalho avaliando a produtividade e eficiência econômica em sistema adensado do maracujazeiro na região de estudo, Sul de Minas Gerais.

Objetivou-se com este trabalho avaliar o efeito de diferentes densidades de plantio na produção e rentabilidade econômica do maracujazeiro-amarelo, no município de São Tiago, Minas Gerais.

\section{MATERIAL E MÉTODOS}

O experimento foi instalado em outubro de 2001, com mudas produzidas em tubetes e levadas ao campo quando atingiram $20 \mathrm{~cm}$ de altura. $\mathrm{O}$ experimento foi conduzido em área de pomar comercial, da Fazenda Sant'ana, município de São Tiago, $\mathrm{MG}$ ( $44^{\circ} 36^{\prime} \mathrm{O}$ e $\left.20^{\circ} 54^{\prime} \mathrm{S}\right)$. O delineamento experimental utilizado foi o de blocos casualizados com 7 (sete) tratamentos e 4 (quatro) repetições. Os tratamentos constituíram-se de diferentes densidades na linha de plantio: $\mathrm{T} 1=1,0 \mathrm{~m}$ (3.330 plantas $/ \mathrm{ha}), \mathrm{T} 2=2,0 \mathrm{~m}(1.660$ plantas/ha), T3=3,0 $\mathrm{m}$ (1.110 plantas/ha), T4= 4,0 $\mathrm{m}$ (830 plantas/ha), T5 $=1,0 \mathrm{~m}(3.330 / 1.660$ plantas $/ \mathrm{ha}), \mathrm{T} 6=1,5 \mathrm{~m}$ (2.220/1.110 plantas/ha) e T7 $=2,0 \mathrm{~m}$ (1.660/830 plantas/ ha). Nos tratamentos T5, T6 e T7, foi feito desbaste de plantas alternadas logo após o término da colheita da primeira safra. Para a análise estatística dos dados da primeira safra, foram utilizados apenas os tratamentos $\mathrm{T} 1$, T2, T3, T4 e T6, pois os tratamentos T5 e T7 só diferem de T1 e T2 a partir da segunda safra. Cada parcela constituise de $36 \mathrm{~m}^{2}$, com $12 \mathrm{~m}$ de comprimento por 3,0 $\mathrm{m}$ de largura, compreendendo o espaçamento entre linhas.

As adubações de formação e produção, a condução e os demais tratos culturais foram realizados de acordo Quaggio \& Piza Júnior (1998) e Ruggiero et al. (1996), porém, sem polinização artificial.

Foram contados e pesados todos os frutos de cada parcela, que serviu para estimar a produtividade (t/ha).

Custo de produção é a soma de todos os valores (insumos) e operações (serviços) utilizados no processo produtivo de certa atividade, incluindo os respectivos custos alternativos ou de oportunidade. Para efeito da análise do custo alternativo fixo (CAfixo) dos recursos produtivos alocados na produção do maracujazeiro, considerou-se a taxa de juros de $12 \%$ a. a.

A depreciação de máquinas e equipamentos não foram consideradas, por utilizar o preço de alocação, prática adotada na região, por se tratar de produtores com no máximo um hectare com maracujazeiro e distribuindo o custo da espaldeira nos três anos de vida útil da cultura, uma vez que a mesma é sempre reformada no início de cada plantio.

\section{Custo fixo}

O custo de cada recurso fixo foi calculado somandose o custo alternativo do fator produtivo.

Como custo fixo, foram considerados o arrendamento da terra, imposto territorial rural (ITR) e $50 \%$ do valor do arame utilizado na espaldeira (amortização), independente da quantidade de mudas plantadas por unidade de área (espaçamento), enquanto os fatores variáveis estão associados diretamente às quantidade de mudas.

O custo alternativo fixo foi calculado pela taxa de juros real de $12 \%$ a.a., para cada uma das categorias de recursos do custo fixo. Essa taxa é próxima a uma remuneração mínima no mercado financeiro.

\section{Custo variável}

O custo de cada variável foi calculado pelo desembolso realizado para a aquisição de produtos e serviços somado ao custo alternativo. Os recursos variáveis e a forma de operacionalização utilizada foram:

Mão-de-obra: referente às operações de plantio e condução da planta (tutoramento, e poda de condução), empregadas especialmente para cada unidade de espaçamento, além das outras operações utilizadas independentemente do espaçamento adotado.

Insumos: corresponde ao gasto com aquisição de fertilizantes químicos, matéria orgânica, alocação de máquinas e equipamentos, defensivos e micronutrientes. 
Os preços de insumos e mão-de-obra foram levantados na região da localização do experimento.

$\mathrm{O}$ preço do quilograma ou receita média $(\mathrm{RMe})$ de maracujá recebido pelo produtor foi de $\mathrm{R} \$ 0,40$ nas 3 safras, preço pago pela indústria de suco. Porém, como o maracujazeiro é uma cultura destinada tanto à industria como ao mercado ao natural, na análise econômica, foi considerado o preço médio pago pela indústria ( $\mathrm{R} \$ 0,40 /$ $\mathrm{kg}$ ) e preço médio pago pela comercialização de $50 \%$ dos frutos entregues na indústria e 50\% do mercado de frutas frescas, calculado pela fórmula:

$$
\text { Preço }=\frac{\mathrm{R} \$ 0,40 / \mathrm{kg}+\mathrm{R} \$ 0,70 / \mathrm{kg}}{2}=\mathrm{R} \$ 0,55 / \mathrm{kg}
$$

Esse sistema foi considerado neste trabalho como sistema misto. É uma metodologia utilizada para medir esta possibilidade, pois os frutos atingem preços diferenciados dependendo da classe de tamanho (cinco classes), não distingüidas nesse trabalho, pois, em mercado menos exigente, a comercialização pode ter preço único, como o que foi pago para o maracujá daquela região $\mathrm{R} \$ 0,70 / \mathrm{ha}$.

A análise econômica simplificada dos custos serve para verificar se e como os recursos empregados em um processo de produção estão sendo remunerados, possibilitando também verificar como está a rentabilidade da atividade em questão, comparada a outras alternativas de emprego do tempo e capital (REIS, 2002).

As receitas líquidas médias provenientes das diferentes densidades de plantas deste estudo foram calculadas pela diferença entre o valor da produção de 1 (um) hectare e o custo total médio por hectare.

O ponto de nivelamento representa lucro normal $(\mathrm{RT}=\mathrm{CT})$ e ponto de resíduo ocorre quando o resíduo é nulo $(\mathrm{RT}=\mathrm{CopT})$.

Os pontos de nivelamento qn e qr permitem uma avaliação da situação presente estudada, com possíveis situações de otimização com as possibilidades de se chegar a elas.

Os valores do ponto de nivelamento $\left(q_{n}\right)$ e de resíduo $\left(\mathrm{q}_{\mathrm{r}}\right)$ serão encontrados pelas fórmulas da produção de cobertura total $\left(\mathrm{P}_{\mathrm{ct}}\right)$ e produção de cobertura operacional $\left(\mathrm{P}_{\text {cop }}\right)$, devido à impossibilidade de se utilizar a fórmula de $\mathrm{q}_{\mathrm{n}}$ e $\mathrm{q}_{\mathrm{r}}$, por apresentar receita média menor que o custo variável médio ( $\mathrm{RMe}<\mathrm{CVMe}$ ) e receita média menor que o custo opecional variável médio (CopVMe), para alguns tratamentos. Assim, calculou-se a produção de cobertura total $\left(\mathrm{p}_{\mathrm{cc}}\right)$ e produção de cobertura operacional $\left(\mathrm{p}_{\text {cop }}\right)$. Aplicando-se as expressões:

$$
\mathrm{Pct}=\frac{C T}{(\text { preço })} \quad \mathrm{e} \quad \mathrm{Pcop}=\frac{\text { CopT }}{(\text { preço })}
$$

Em que: Pct - ponto de cobertura total; CT - custo total; Pcop - ponto de cobertura operacional; CopT - custo operacional total; $\mathrm{CVMe}$ - custo variável médio, $\mathrm{CopVMe}-$ custo operacional variável médio, RT - receita total; CT custo total;

\section{RESULTADOS E DISCUSSÃO}

Houve diferenças estatísticas entre os tratamentos ao nível de 5\% de probabilidade pelo teste Tukey, para a produtividade da safrinha e produtividade total (Figura 1).

Analisando a produção acumulada das três safras, verifica-se que os espaçamentos menores ou iguais a três metros na linha de plantio, foram mais produtivos que o espaçamento de 4 metros, por apresentar produção menor tanto na safrinha quanto na segunda safra. Resultados semelhantes foram encontrados por Pace \& Araújo (1981), em que a maior produtividade, referente as duas safras analisadas $(57,2 \mathrm{t} / \mathrm{ha})$ foi obtida no espaçamento de 2,5 m x 1,0 m; e por Kits et al. (1996) que, obtiveram nas três safras, produtividade de 51,9 t/ha no espaçamento de $2,0 \times 1,75 \mathrm{~m}$.

Analisando o percentual de participação dos itens que compõem os custos totais de produção do maracujazeiro para as diferentes densidades de plantio, verifica-se que os custos fixos representam apenas 3,67\% do custo final da produção do maracujá e o custo variável 96,33\% para a média geral dos tratamentos, com pouca variação entre os mesmos (Tabela 1).

O custo fixo na cultura do maracujazeiro é baixo, por ser uma planta de ciclo médio ( \pm 3 anos), parte ou totalidade dos frutos destinados à indústria é característica de pequena produção, não exige benfeitoria, como casa - de - embalagem, caixas de colheita. Na região, onde situou-se este experimento, os produtores comercializam os frutos apenas para a indústria, colhendoos em sacos de aniagem, não utilizam manejo pós-colheita, não possuem casa - de - embalagem e neste caso, também não se usou sistema de irrigação. Kits et al. (1996) também verificaram baixos custos fixos para a cultura do maracujazeiro. 


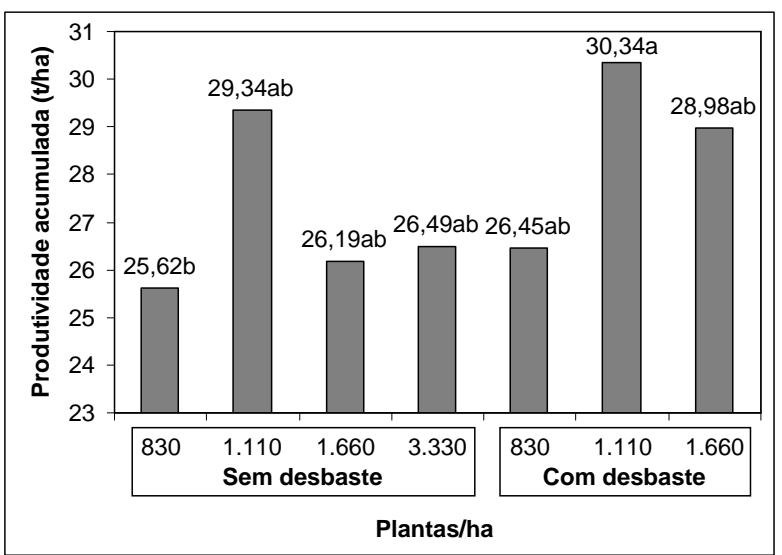

FIGURA 1 - Produtividade acumulada de três anos (t/ha) do maracujazeiro-amarelo sob diferentes densidades de plantas. Lavras,MG, UFLA, 2004.

Mão-de-obra, fertilizantes, defensivos, espaldeiramento e mudas foram os principais responsáveis pelo aumento dos custos variáveis no custo total de produção. Os fertilizantes corresponderam a variação de $23,54 \%$ no tratamento T7 (830 pl/ha com desbaste) a $24,00 \%$ no tratamento T4 (830 pl/ha sem desbaste), do total dos custos, pouca variação em decorrência de que apenas a dosagem dos micronutrientes foram calculadas por planta e não por hectare como dos macronutrientes. Os defensivos corresponderam a variação de $16,67 \%$ no tratamento T5 a $18,57 \%$, dos custos totais, no tratamento T4. As mudas proporcionaram a maior amplitude de variação em relação aos insumos, diminuindo de $0,05 \%$ na maior densidade para $0,01 \%$ na menor densidade.

O custo total de produção das três safras variou de $\mathrm{R} \$ 13.333,14 /$ ha (treze mil, trezentos e trinta e três reais e quatorze centavos) na densidade de 830 plantas/ha a $\mathrm{R} \$ 14.853,87 /$ ha (quatorze mil, oitocentos e cinqüenta e três reais e oitenta e sete centavos) na densidade de 3.330 plantas/ha com desbaste.

Os custos variáveis de produção das três safras variaram de $\mathrm{R} \$ 12.817,69 /$ ha para a densidade de 830 plantas/ ha a $R \$ 14.338,43 /$ ha na densidade de 3.330 plantas/ha com desbaste de plantas. E os custos fixos não apresentaram variação entre as densidades de plantio, por não dependerem do número de plantas e sim pelo tamanho da área cultivada, representados pelo valor de $\mathrm{R} \$ 515,47 / \mathrm{ha}$.

Os custos econômicos e operacionais médios da produção do maracujá aumentaram com a densidade de plantas, mas diminuíram com o aumento da produtividade. Assim, baseado nesta relação, o tratamento T3, com o $2^{\circ}$ menor custo, mas com a $2^{\mathrm{a}}$ maior produtividade, possui o menor custo total médio (CTMe), bem como, os custos econômicos médios e os custos operacionais médio.

TABELA 1 - Porcentagem dos custos fixos e variáveis da produção de maracujá nas diferentes densidades de plantio, provenientes das três safras acumuladas. Lavras,MG, UFLA, 2004.

\begin{tabular}{llllllllll} 
Custos Fixos e Variáveis $^{*}$ & \multicolumn{8}{c}{ Porcentagem do custo total } \\
& T1 & T2 & T3 & T4 & T5 & T6 & T7 & Média \\
\hline
\end{tabular}

\begin{tabular}{|c|c|c|c|c|c|c|c|c|}
\hline \multicolumn{9}{|l|}{ Custos Fixos } \\
\hline Espaldeira (amortização) $)^{1}$ & 1,08 & 1,15 & 1,18 & 1,20 & 1,08 & 1,12 & 1,15 & 1,14 \\
\hline Terra & 2,02 & 2,16 & 2,22 & 2,25 & 2,02 & 2,10 & 2,16 & 2,13 \\
\hline ITR & 0,003 & 0,003 & 0,003 & 0,003 & 0,003 & 0,003 & 0,003 & 0,00 \\
\hline Custo alternativo & 0,37 & 0,40 & 0,41 & 0,41 & 0,37 & 0,39 & 0,40 & 0,39 \\
\hline CFT & 3,47 & 3,70 & 3,82 & 3,87 & 3,47 & 3,61 & 3,71 & 3,67 \\
\hline \multicolumn{9}{|l|}{ Custos variáveis } \\
\hline Insumos $^{2}$ & 60,89 & 60,69 & 61,14 & 61,16 & 60,84 & 60,61 & 60,56 & 60,84 \\
\hline Serviços & 25,30 & 25,29 & 24,74 & 24,68 & 25,34 & 25,45 & 25,41 & 25,17 \\
\hline Custo alternativo & 10,34 & 10,32 & 10,31 & 10,30 & 10,34 & 10,33 & 10,32 & 10,32 \\
\hline \multirow[t]{2}{*}{ CVT } & 96,53 & 96,30 & 96,18 & 96,13 & 96,53 & 96,39 & 96,29 & 96,33 \\
\hline & 100,0 & 100,0 & 100,0 & 100,0 & 100,0 & 100,0 & 100,0 & \\
\hline CT & 0 & 0 & 0 & 0 & 0 & 0 & 0 & 100,00 \\
\hline
\end{tabular}

${ }^{1}$ - Considerou-se $50 \%$ do valor do arame, bem utilizável pelo menos em dois cultivos.

2. Aluguel de máquinas e mão-de-obra empregadas nas atividades de correção do solo.

* CFT = custo fixo total; CVT = custo variável total e CT = custo total. 
TABELA 2 - Custos econômicos e operacionais médios da produção do maracujá, em diferentes densidades de plantio, provenientes das três safras acumuladas. Lavras,MG, UFLA, 2004.

\begin{tabular}{|c|c|c|c|c|c|c|c|}
\hline $\begin{array}{c}\text { Tratamentos } \\
\text { Espaçamento }(\mathbf{m})\end{array}$ & Planta/ha & $\begin{array}{c}\text { CFMe } \\
(\mathbf{R} \$)\end{array}$ & $\begin{array}{c}\text { CVMe } \\
(\mathrm{R} \$)\end{array}$ & $\begin{array}{c}\text { CTMe } \\
(\mathbf{R} \$)\end{array}$ & $\begin{array}{c}\text { CopFMe } \\
(\mathrm{R} \$)\end{array}$ & $\begin{array}{c}\text { CopVMe } \\
(\mathrm{R} \$)\end{array}$ & $\begin{array}{r}\text { CopTMe } \\
(\mathrm{R} \$) \\
\end{array}$ \\
\hline $\mathrm{T} 1=3,0 \times 1,0$ & 3.330 & 0,019 & 0,54 & 0,56 & 0,02 & 0,48 & 0,50 \\
\hline $\mathrm{T} 2=3,0 \times 2,0$ & 1.660 & 0,020 & 0,51 & 0,53 & 0,02 & 0,46 & 0,47 \\
\hline $\mathrm{T} 3=3,0 \times 3,0$ & 1.110 & 0,018 & 0,44 & 0,46 & 0,02 & 0,40 & 0,41 \\
\hline $\mathrm{T} 4=3,0 \times 4,0$ & 830 & 0,020 & 0,50 & 0,52 & 0,02 & 0,45 & 0,46 \\
\hline $\begin{array}{l}\text { T5=3,0 x } 1,0 \\
\text { com desbaste }\end{array}$ & 1.660 & 0,018 & 0,49 & 0,51 & 0,02 & 0,44 & 0,46 \\
\hline $\begin{array}{l}\mathrm{T} 6=3,0 \times 1,5 \\
\text { com desbaste }\end{array}$ & 1.110 & 0,017 & 0,45 & 0,47 & 0,02 & 0,40 & 0,42 \\
\hline $\begin{array}{l}\mathrm{T} 7=3,0 \times 2,0 \\
\text { com desbaste }\end{array}$ & 830 & 0,019 & 0,51 & 0,52 & 0,02 & 0,45 & 0,47 \\
\hline Média & & 0,019 & 0,49 & 0,51 & 0,02 & 0,44 & 0,46 \\
\hline
\end{tabular}

CFMe - Custo Fixo Médio; CVMe - Custo Variável Médio; CTMe-Custo Total Médio; CopFMe - Custo Operacional Fixo Médio; CopVMe - Custo Operacional Variável Médio; CopTMe - Custo Operaional Médio.

Os resultados dos custos médios da produção de maracujá, em relação as diferentes densidades de plantas estão na Tabela 2. O custo total médio (CTMe) apresentou uma diminuição quando diminuiu a densidade de plantas, variando de $\mathrm{R} \$ 0,46 / \mathrm{kg}$ no plantio com densidade de 1.110 plantas/ha a $\mathrm{R} \$ 0,56 / \mathrm{kg}$ na densidade de 3.330 plantas $/ \mathrm{ha}$.

Observando a Figura 1 e a Tabela 2, verifica-se que o custo total médio diminuiu com o aumento da produtividade, apesar das maiores produtividades serem observadas em plantios mais adensados (3.330 e" 1.110 plantas ha), que apresentam os maiores custos totais.

Conforme informações contidas na Tabela 2, no sistema de comercialização exclusivamente para indústria com receita média (RMe) de $\mathrm{R} \$ 0,40 / \mathrm{kg}$, observa-se que $\mathrm{RMe}<\mathrm{CTMe}$, indicando que em todos os tratamentos a situação é de resíduo, especificamente resíduo negativo (Rme<CopTMe).

Observa-se também, que não há cobertura dos custos de curto prazo ou o chamado capital de giro ( $\mathrm{RMe}<\mathrm{CopVMe}$ ), assim, ao persistir tal situação, há a necessidade de subsidiar os recursos variáveis ou a própria saída da atividade, diminuindo os prejuízos.

Já a análise da situação de comercialização da fruta de forma mista (50\% para indústria e 50\% para consumo in natura $-\mathrm{R} \$ 0,55 / \mathrm{kg}$ ), apenas a densidade de 3.330 plantas/ ha proporcionou resíduo $(\mathrm{RMe}<\mathrm{CTMe})$, especificamente resíduo positivo (CTMe $<\mathrm{RMe}>\mathrm{CopTMe}$ ), cobrindo todos os custos variáveis e parte dos custos fixos. Para as demais densidades de plantio, a situação de lucro supernormal existe (RMe $>\mathrm{CTMe}$ ), indicando que para qualquer outra densidade de plantas, o cultivo de maracujá na região de São Tiago a médio e longo prazo é de expansão com a entrada de novos produtores, tornando a atividade mais competitiva, desde que haja essa diversificação na comercialização.

Na comercialização para indústria, a receita líquida variou de $\mathrm{R} \$-4.247,47 / \mathrm{ha}$ no tratamento $\mathrm{T} 1$ a $\mathrm{R} \$-1.763,14$ / ha no tratamento T3 (Tabela 3).

Considerando o sistema de comercialização "Mista", a receita líquida variou de R \$-274,27/ha no tratamento T1 a R $\$ 2.637,56 /$ ha no tratamento T3. Neste caso, a maior eficiência técnica (produtividade em T6) não coincidiu com a maior eficiência econômica, por causa dos maiores custos do plantio adensado.

Pires \& São José (1994) afirmam que a cultura do maracujá sempre foi caracterizada por grandes oscilações de preços pagos aos fruticultores, que por sua vez, ajustam sua produção de acordo com essas variações, o que reflete no total da área plantada. É que, além do preço, os custos de produção e a rentabilidade do maracujazeiro variam de região para região, em função do nível de conhecimento e infraestrutura do fruticultor, destino da produção (indústria e/ou fruta fresca), condições edafoclimáticas, ocorrência de pragas e doenças, distância do mercado consumidor, etc.

Portanto, fica claro que neste momento a rentabilidade econômica desta cultura depende muito do preço do maracujá, principalmente em anos que a produtividade é baixa, causada ora por veranicos antecedendo a emissão floral, ora por excesso de precipitação pluviométrica durante o florescimento. 
Nesse contexto, em São Tiago e região, o preço do fruto para indústria nos anos de 2002, 2003 e 2004, foi de aproximadamente US $\$ 0,133 / \mathrm{kg}$ (câmbio de US\$ 1,00 : R \$ 3,00), portanto, abaixo do limite inferior do preço histórico de US\$0,18/kg a US\$0,25/kg (GUEDES \& VILELA, 1999) e próximo ao limite inferior dos valores entre, os pagos pelas indústrias de suco, de US\$0,10/kg a US\$0,40/kg (PIRES \& SÃO JOSÉ, 1994).

Para uma receita média de $\mathrm{R} \$ 0,40 / \mathrm{kg}$, a quantidade de frutos produzidos para cobrir todos os custos de produção $\left(\mathrm{p}_{\mathrm{ct}}\right)$ ou para cobrir pelo menos os custos operacionais $\left(\mathrm{p}_{\text {cop }}\right)$ foi maior que a produção em qualquer um dos tratamentos (Tabela 4).

Para a receita média de $\mathrm{R} \$ 0,55 / \mathrm{kg}$, a produção mínima para que não haja perda econômica no tratamento com maior receita líquida (T3), é de $24.542 \mathrm{~kg} / \mathrm{ha}\left(\mathrm{p}_{\mathrm{ct}}\right)$, fato comprovado, pois a produção desse tratamento foi de $29.338 \mathrm{~kg} / \mathrm{ha}$.

No tratamento T1, que apresentou resíduo, com receita líquida de -R $\$ 274,27 / \mathrm{kg}$, a quantidade de frutos produzidos para cobrir todos os custos de produção $\left(26.987 \mathrm{~kg} \mathrm{ha}^{-1}\right)$ foi maior que a produção de frutos $\left(26.488 \mathrm{~kg} \mathrm{ha}^{-1}\right)$.

Considerando o preço histórico do maracujá para indústria de US\$0,18/kg ou US\$0,25/kg (GUEDES \& VILELA, 1999), e os custos de produção apresentados pelo Agrianual (2004), a produção de cobertura total, necessária para cobrir todos os custos de produção, é de $42.392 \mathrm{~kg} \mathrm{ha}^{-1} / 3$ anos a $58.878 \mathrm{~kg} \mathrm{ha}^{-1} / 3$ anos, respectivamente, bem superior à produtividade encontrada neste trabalho em todos os tratamentos.

No entanto, considerando uma produtividade baixa, como a média nacional $\left(9,9 \mathrm{t} \mathrm{ha}^{-1}\right)$ e deste experimento $(8,5$ a 10,1 $\mathrm{t} \mathrm{ha}^{-1}$ ), os gastos com insumos e serviços são menores. Assim, a AFRUVEC apresenta custos de produção bem abaixo dos custos cotados pelo Agrianual (2004) e são semelhantes ao custos apresentados nesse trabalho (SILVA et al., 2003). Para os custos de produção apresentados pela AFRUVEC, a produção de cobertura total para o preço de $\mathrm{R} \$ 0,40 / \mathrm{kg}$, necessita de $30.102 \mathrm{~kg} \mathrm{ha}^{-1} / 3$ anos e $21.893 \mathrm{~kg}^{-}$ $1 / 3$ anos para o preço de $\mathrm{R} \$ 0,55 / \mathrm{kg}$, semelhante aos valores encontrados nesse trabalho.

TABELA 3 - Receita Líquida (RL) da produção do maracujá, em diferentes densidades de plantio, provenientes das três safras acumuladas. Lavras,MG, UFLA, 2004.

\begin{tabular}{|c|c|c|}
\hline $\begin{array}{c}\text { Tratamentos } \\
\text { Espaçamento (m) }\end{array}$ & $\begin{array}{c}\text { RL (Industria)* } \\
(\mathbf{R} \$ / \mathbf{h a})\end{array}$ & $\begin{array}{l}\text { RL (Misto) } \\
\text { (R\$/ha) }\end{array}$ \\
\hline $\mathrm{T} 1=3,0 \times 1,0$ & $-4.247,47$ & $-274,27$ \\
\hline $\mathrm{T} 2=3,0 \times 2,0$ & $-3.443,42$ & 484,78 \\
\hline $\mathrm{T} 3=3,0 \times 3,0$ & $-1.763,14$ & $2.637,56$ \\
\hline $\mathrm{T} 4=3,0 \times 4,0$ & $-3.086,34$ & 756,21 \\
\hline $\mathrm{T} 5=3,0 \times 1,0$, com desbaste de plantas & $-3.262,27$ & $1.084,58$ \\
\hline $\mathrm{T} 6=3,0 \times 1,5$, com desbaste de plantas & $-2.127,34$ & $2.424,11$ \\
\hline $\mathrm{T} 7=3,0 \times 2,0$, com desbaste de plantas & $-3.297,11$ & 670,09 \\
\hline
\end{tabular}

* Considerou-se a receita líquida para dois sistemas de comercialização: Indústria, o qual oscila o preço da fruta em torno de $\mathrm{R} \$ 0,40 / \mathrm{kg}$, durante o período de estudo e o sistema Misto ( $\mathrm{R} \$ 0,55 / \mathrm{kg}$ ), o qual além da opção de entregar para a indústria, o produtor pode também comercializar o fruto ao mercado de frutas frescas, com preço oscilando em torno de $\mathrm{R} \$ 0,70 / \mathrm{kg}$.

TABELA 4 - Produção de cobertura total $\left(\mathrm{p}_{\mathrm{ct}}\right)$ e produção de cobertura operacional $\left(\mathrm{p}_{\mathrm{cop}}\right)$ da produção do maracujá, em diferentes densidades de plantas, provenientes das três safras acumuladas, avaliada pelo sistema de comercialização para indústria e mercado de fruta para mesa. Lavras,MG, UFLA, 2004.

\begin{tabular}{|c|c|c|c|c|}
\hline \multirow{2}{*}{$\begin{array}{c}\text { Tratamentos } \\
\text { Espaçamento (m) }\end{array}$} & \multicolumn{2}{|c|}{ Industria } & \multicolumn{2}{|c|}{ Industria/Mesa } \\
\hline & $\begin{array}{c}\mathbf{p}_{\text {ct }} \\
(\mathbf{k g} / \mathbf{h a})\end{array}$ & $\begin{array}{c}\mathbf{p}_{\text {cop }} \\
(\mathbf{k g} / \mathbf{h a})\end{array}$ & $\begin{array}{c}\mathbf{p}_{\mathrm{ct}} \\
(\mathrm{kg} / \mathbf{h a})\end{array}$ & $\begin{array}{c}\mathbf{p}_{\text {cop }} \\
(\mathrm{kg} / \mathrm{ha})\end{array}$ \\
\hline $\mathrm{T} 1=3,0 \times 1,0$ & 37.107 & 33.131 & 26.987 & 24.095 \\
\hline $\mathrm{T} 2=3,0 \times 2,0$ & 34.797 & 31.068 & 25.307 & 22.595 \\
\hline $\mathrm{T} 3=3,0 \times 3,0$ & 33.746 & 30.130 & 24.542 & 21.913 \\
\hline $\mathrm{T} 4=3,0 \times 4,0$ & 33.333 & 29.761 & 24.242 & 21.645 \\
\hline $\mathrm{T} 5=3,0 \times 1,0$, com desbaste de plantas & 37.135 & 33.156 & 27.007 & 24.113 \\
\hline $\mathrm{T} 6=3,0 \times 1,5$, com desbaste de plantas & 35.661 & 31.841 & 25.936 & 23.157 \\
\hline $\mathrm{T} 7=3,0 \times 2,0$, com desbaste de plantas & 34.691 & 30.974 & 25.230 & 22.526 \\
\hline
\end{tabular}




\section{CONCLUSÕES}

a) Na região de São Tiago/MG, o custo total de produção aumentou com o adensamento de plantio, enquanto a produção apresentou tendência de redução nos espaçamentos adensados.

b)A produção do maracujazeiro destinada exclusivamente para indústria, com preço e custos vigentes, constitui-se em uma atividade com resíduo negativo (prejuízo) independente do espaçamento.

c) O espaçamento de 3,0 x 3,0 m, sem desbaste de plantas proporcionou a maior receita líquida.

\section{REFERÊNCIAS BIBLIOGRÁFICAS}

AGRIANUAL. Anuário da agricultura brasileira 2004. São Paulo: FNP Consultoria, 2004. 601 p.

GOMES, R. P. Fruticultura brasileira. 11. ed. São Paulo: Nobel, 1987. 446 p.

GUEDES, L. de O.; VILELA, P. S. O mercado do maracujá. Belo Horizonte: FAEMIG, 1999. 16 p. (Série Fruticultura).

KITS, H.; FELDENS, A. M.; MANICA, I.; FIORAVANÇO, J. C. Análise econômica de densidade de plantio do maracujá-amarelo no município de Porto Lucena, RS. Pesquisa Agropecuária Brasileira, Brasília, v. 31, n. 7, p. 497-502, jul. 1996.

LEDERMAN, I. E.; GONZAGA NETO, L.; BEZERRA, J. E. F.; PEDROSA, A. C. Rendimento do maracuazeiro amarelo (Passiflora edulis Sims. f. flavicarpa Deg.) sob diferentes densidades de plantio. In: CONGRESSO BRASILEIRO DE FRUTICULTURA, 8., 1986, Brasília, DF. Anais... Brasília, DF: Sociedade Brasileira de Fruticultura, 1986. p. 397-401.

MANICA, I.; RITZINGER, R.; MUNDSTOCK, E. C.; MARODIN, G. A. B.; KOLLER, O. C. Efeito de seis espaçamentos de plantio no $2^{\circ}$ ano de produção do maracujá amarelo (Passiflora edulis f.flavicarpa Deg.) em Guaíba/RS. Revista Brasileira de Fruticultura, Cruz das Almas, v. 11, n. 1, p. 25-30, abr. 1989.
MENZEL, C. M.; HAYDON, G. F.; DOOGAN, V. J.; SIMPSON, D. R. New standard leaf nutrient concentrations for passionfruit based on seasonal phenology and leaf composition. Jornal of Horticultural Science, Ashford, v. 26, n. 2, p. 215-229, 1993.

PACE, C. A. M.; ARAÚJO, C. M. Efeito de densidade de plantio na cultura do maracujá-amarelo (Passiflora eduli $\mathrm{f}$. flavicarpa Deg.). In: CONGRESSO BRASILEIRO DE FRUTICUlTURA, 6., 1981, Recife. Anais... Recife: Sociedade Brasileira de Fruticultura, 1981. p. 972-982.

PIRES, M. de M.; SÃO JOSÉ, A. R. Custo de produção e rentabilidade da cultura do maracujazeiro. In: SÃO JOSÉ, A. R. (Ed.). Maracujá: produção e mercado. Vitória da Conquista: UESB, 1994. p. 223-233.

QUAGGIO, J. A.; PIZA JÚNIOR, C. T. Nutrição e adubação da cultura do maracujá. In: RUGGIERO, C. (Ed.). Maracujá: do plantio à colheita. Jaboticabal: Funep, 1998. p. 130-156.

RAMOS, J. D. Cultura do maracujazeiro. Aracajú: SUDAP/ COPEA/EEB, 1986. 16 p. (Circular técnico, 2).

REIS, R. P. Fundamentos de economia aplicada. Lavras: UFLA/FAEPE, 2002. 95 p. (Texto acadêmico).

RUGGIERO, C.; SÃO JOSÉ, A. R.; VOLPE, C. A.; OLIVEIRA, J. C. de; DURIGAN, J. F.; BAUMGARTNER, J. G.; SILVA, J. R.; NAKAMURA, K.; FERREIRA, M. E.; KAVATI, R.; PEREIRA, V. de P. Maracujá para exportação: aspectos técnicos da produção. Brasília, DF: Embrapa-SPI, 1996. 64 p. (Publicações técnicas FRUPEX, 19).

SILVA, A. V. C. da; ANDRIAZZI, C. V. G.; CAPUTO, M. M.; SEVALI, P. L. Custos de produção. In: TODAFRUTA. Maracujá. Disponível em: 'LWww.todafruta.com.br $/ \geq 1$. Acesso em: 27 nov. 2003. 